\title{
Cognizing mediating: Unpacking the entanglement of artifacts with collective minds
}

\author{
Gerry Stahl
}

Published online: 17 May 2012

(C) International Society of the Learning Sciences, Inc.; Springer Science+Business Media, LLC 2012

The age of simple objects like well-designed artifacts, minds confined inside of skulls, and cultures cloistered in the tacit background has been left in the fading past according to current socio-cultural theory. We are now enmeshed in dialectical processes of social enactment, whereby designed objects continue to evolve well after they enter into the structuring of our thought patterns.

Biological human evolution has long since transformed itself into cultural evolution, proceeding at an exponential pace. Along the way, thought overcame the limits of individual minds to expand with the power of discourses, inscriptions, digital memories, computational devices, technological infrastructures, computer-supported group cognition, and virtual communities. Both human cognition and its mediation by technological artifacts morph from fixed nouns into process verbs, like "cognizing mediating"-where human cognition and technological media shape each other in ways we are just beginning to conceptualize.

The owl of Minerva flies only at night, according to Hegel's (1807/1967) metaphor: theory - which is one's time grasped in concepts - lags behind the continuous unfolding of practice. As today's viral software successes rapidly outstrip our design theories, we must try to understand the ways in which new generations of users adopt and adapt their digital tools, thereby defining and redefining their conceptual, social, and pragmatic ties to their worlds. Hegel theorized the dialectic between subject and object, proposing that the identity of the human subject is formed when a subject subjects an object to goal-oriented design (Stahl 2006, p. 333f), creating an artifact within the effort to forge intersubjectivity and its spin-off, the individual's self.

Vygotsky (1930/1978) recognized the role of double stimulation in mediated cognizing: that the subject's access to an object is mediated by tools such as hammers, names, and physical-symbolic inscriptions, so that in higher-order human cognizing we are stimulated by both an intentional object and a cognizing-mediating tool. It is this mediation of cognition by artifacts and via other people that opens the zone of proximal development, allowing the individual mind to first exceed and then later extend its limits. Engeström's (1987) concept of expansive learning added the cultural dimensions from Marx' social theory to Vygotsky's

G. Stahl $(\bowtie)$

Drexel University, Philadelphia, USA

e-mail: Gerry@ijCSCL.org 
simple triangle of subject-artifact-object. Henceforth, socio-technical understandings of artifacts have to situate them culturally, historically, politically.

We have considered the labyrinthine nature of the artifact's affordances previously within theories of human-computer interaction (Hutchins 1999; Norman 1991), cognitive science (Gibson 1979; Hutchins 1996) and CSCL (Bonderup Dohn 2009; Dwyer and Suthers 2006; Jones et al. 2006; Suthers 2006; van der Pol et al. 2006). In particular, based on MerleauPonty's (1945/2002) philosophy, Bonderup Dohn argued that the affordances of an artifact were potentials realized in response to human behaviors.

In this issue's opening essay, Maarten Overdijk, Wouter van Diggelen, Paul A. Kirschner $\&$ Michael Baker explore the nature of artifacts by comparing the theory of affordances with the theories of structuration and of instrumental genesis. Structuration (Giddens 1984; Orlikowski 2008) is a well known theory developed to account for the dialectic between social structures and the local interactions which are both constrained by these structures and reproduce them. Instrumental genesis is a recent theory developed in France by Pierre Rabardel and his colleagues. This issue of ijCSCL introduces the theory of instrumental genesis to the CSCL community and explores how the theory might impact work in CSCL, at methodological, technological, and theoretical levels.

Our first article compares the three major recent theories about the interaction between artifacts and people, using a concrete case study of a typical CSCL setting. It argues in favor of the general approach of instrumental genesis as an analysis of the micro-genesis of artifacts and as the best available description of the nature of tools, particularly for CSCL. The theory of affordances tends to focus on the individual, for instance with Gibson's biological perspective or Norman's use of mental models, or Piaget's schemas in individual minds. In contrast, the sociological theory of structuration focuses on the societal or cultural level. The theory of instrumental genesis can more naturally be applied to the small-group collective level central to CSCL, as the first article does in discussing how triads of students enacted a feature of an argumentation-support software system.

The paper presents a "theoretically grounded" conception of the artifact-agent connection. A next step would be to explore an empirically grounded analysis of the connection. While the article referred to data from a CSCL experiment, it simply used high-level descriptions of the data to illustrate aspects of the theories being described. It will be important in the future to analyze such data in detail to see if the connections of groups of students to computer-support systems follow the contours of one or more of the three theories, or whether they display different lines of development. Furthermore, it will be useful to consider more complex technologies, whole meso-level infrastructures (Jones et al. 2006) rather than isolated functions. For instance, in an online course, small groups may have to negotiate the coordinated use of hundreds of functions in Blackboard, Google search, Wikipedia, Facebook, Google Docs, iChat, Gmail, Word, and PowerPoint in order to produce a 1-week assignment. Such an undertaking invokes the use of individual experience or expertise, established social practices in the school culture, consideration of course requirements and project goals, as well as collaborative discourse and trials by the small groups. The resultant computer-supported effort assembles and interprets a complex technical infrastructure, increases the expertise of the group participants, and provides a medium for group knowledge building. The connection of the collaborative group with the technical infrastructure continuously evolves through use during a term.

Having glimpsed the potential relevance of the theory of instrumental genesis to CSCL, we turn next to a discussion of that theory within the context of CSCL system design. Jacques Lonchamp returns to these pages after having presented his analyses of CSCL design options (Lonchamp 2006, 2009). He now argues for applying Rabardel's theory by 
expanding Engeström's (1987) Activity Theory triangle of mediations, to explicitly represent both the processes of mutual shaping of agent and artifact and the specific role of the teacher in CSCL classrooms: He pictures the various mediated interconnections among tool, designer, teacher, student, peer, and tutor. Furthermore, he discusses how the agent-artifact connection-embodied in Rabardel's conception of the instrument-evolves over time through usage and re-design.

The paper concludes with a review of CSCL system design approaches to supporting "instrumentalization" by teachers and students. Although it comes close to describing design-based research (Brown 1992; Design-Based Research Collective 2003), this review does not name it. Design-based research is a dominant approach within CSCL research to integrating system design, usage analysis, educational research, and practical classroom interventions. It was developed in response to the need to conduct user-centered design of innovative educational software for collaborative groups - a realm lacking in detailed theories, specific analysis methods, adequate software, or design guidelines. Perhaps an explicit combination of Rabardel's theory with data from design-based research projects could provide empirically grounded insights into the mutual shaping of CSCL software and group cognition in on-going design and usage processes.

The third paper, by Giuseppe Ritella \& Kai Hakkarainen, situates Rabardel's theory within the context of knowledge-building practices, as these are conceptualized in recent work at the Scandinavian-led Knowledge Practices Laboratory (KP-Lab). This context is populated with social practices grounded in knowledge-building artifacts (Hakkarainen 2009) and structured in space and time by chronotypes (Ligorio and Ritella 2010). The knowledge-building artifacts are instruments in Rabardel's sense; they provide for advanced forms of Vygotskian double stimulation (Lund and Rasmussen 2008). The whole context is the result of the cultural evolution (Donald 1991; 2001) that led up to our involvement with digital information and communication technologies in an increasingly powerful, distributed, and mediated cognitive universe.

From prehistoric times to the present, the proliferation of forms of inscription (Latour 1990) transformed the human cognitive architecture as profoundly as earlier leaps in biological evolution, allowing radical externalization and collectivization of cognition. In a sense, CSCL aims to push this further, designing collaboration media to foster group cognition that can lead to new forms of individual learning, team knowledge building, and community social practices. To the extent that this is true, we need to design new tasks for computer-supported teams, aiming for cognitive achievements beyond the reach of individual team members without computer supports. The goal of CSCL research should not be to simply demonstrate repeatedly that individuals learn better in online groups, but to design and investigate tasks that go beyond traditional instruction. Recent findings concerning "productive failure" (Kapur and Kinzer 2009; Pathak et al. 2011) illustrate how groups with challenging tasks may be learning in ways that defy standard testing indicators, but that contribute to increased problem-solving skills of the groups and ultimately of their members.

The analysis of instrumental genesis within the framework of knowledge building points to both the potentials of CSCL and the barriers to widespread dissemination. The historical evolution of tools as "epistemic artifacts" can itself be seen as a knowledge-building accomplishment of the greatest cognitive consequence, related to Vygotsky's - perhaps misleadingly named - notion of "internalization" by individuals of skills germinated in intersubjective circumstances. On the other hand, the complexity involved in successful instrumental genesis translates into severe barriers when, for instance, one tries to promote adoption of CSCL technologies, pedagogies, chronotypes, and educational philosophies in established school communities and institutions. Parallel to the difficulties of the students 
struggling to enact the technological affordances are the difficulties of the researchers, trying to document, analyze, and conceptualize the tortuous paths of instrumental genesis in CSCL.

This issue of ijCSCL balances its featured discussion of CSCL theory with important presentations of CSCL pedagogy, CSCL technology, and CSCL analysis. The paper by Carmen G. Zahn, Karsten Krauskopf, Friedrich W. Hesse \& Roy Pea investigates the provision of pedagogical guidance oriented to social interaction versus that oriented to cognitive tasks. An experiment with groups of 16-year-old students using video tools for history lessons indicates that support for their collaborative interactions was more effective than guidance directly related to their assigned tasks. This demonstrates the centrality of issues of adopting and exercising interaction practices in collaborative learning, and has implications for scripting group tasks, orchestrating group work, and guiding group collaboration.

Imagine trying to analyze a large corpus of online collaborative discussion to see how often groups under different conditions articulated specific components of scientific argumentation, such as claims, evidence, critique, etc. The contribution by Jin Mu, Karsten Stegmann, Elijah Mayfield, Carolyn Rosé \& Frank Fischer describes a promising approach to automating such analysis utilizing current and innovative techniques of natural-language processing. The first step - not previously fully automated - is to segment the corpus into utterances (whether phrases, clauses, sentences, or paragraphs) that each expresses a specific component of argumentation. Until this can be automatically accomplished reliably and with generality, the dream of automating the coding of micro-argumentation will remain out of reach. To overcome typical over-generalization to specific training sets, the approach tested here replaces the context-specific terms in a corpus with syntactic descriptors and replaces the nouns with entity categories - e.g., substituting "location" or "city" for "Sydney." This pre-processing allows the software analysis to compute rules that are less context dependent.

Collaborative learning can be much more complex to support and to analyze than individual learning. For instance, computer-based cognitive tutors have been effective in supporting individual learning of traditional school mathematics for years and are used widely in classrooms, but they have rarely been applied successfully to collaborative learning. In the empirical study reported here by Nikol Rummel, Dejana Mullins \& Hans Spada, algebra tutoring technology is combined with scripting to explore potential benefits for small-group learning. As described by the theory of instrumental genesis, the use of new technologies by student groups must be enacted by the students. This means that a comparison of conditions with and without computer supports involves significant differences in the tasks faced by the students, including learning to use the tools and negotiating how to take advantage of them. Different enactments by different teams can obscure statistical measures of learning that average across the cases. As seen in this study, narrative analysis of specific cases can provide incisive insight into how the technologies are being used and how they are actually affecting the group knowledge-building processes. Rigorous research into the effectiveness of CSCL tools can require multiple coordinated methods, responsive to the complexities of the collaborative-learning issues involved, as discussed in this article.

\section{References}

Bonderup Dohn, N. (2009). Affordances revisited: Articulating a Merleau-Pontian view. International Journal of Computer-Supported Collaborative Learning, 4(2), 151-170.

Brown, A. (1992). Design experiments: Theoretical and methodological challenges in creating complex interventions in classroom settings. The Journal of the Learning Sciences, 2(2), 141-178.

Design-Based Research Collective. (2003). Design-based research: An emerging paradigm for educational inquiry. Educational Researcher, 32(1), 5-8. 
Donald, M. (1991). Origins of the modern mind: Three stages in the evolution of culture and cognition. Cambridge: Harvard University Press.

Donald, M. (2001). A mind so rare: The evolution of human consciousness. New York: W. W. Norton.

Dwyer, N., \& Suthers, D. D. (2006). Consistent practices in artifact-mediated collaboration. International Journal of Computer-Supported Collaborative Learning, 1(4), 481-511.

Engeström, Y. (1987). Learning by expanding: An activity-theoretical approach to developmental research. Helsinki: Orienta-Kosultit Oy.

Gibson, J. J. (1979). The ecological approach to visual perception. Boston: Houghton Mifflin.

Giddens, A. (1984). The constitution of society. Outline of the theory of structuration. Berkeley: U of California Press.

Hakkarainen, K. (2009). A knowledge-practice perspective on technology-mediated learning. International Journal of Computer-Supported Collaborative Learning, 4(2), 213-231.

Hegel, G. W. F. (1807/1967). Phenomenology of spirit (J. B. Baillie, Trans.). New York, NY: Harper \& Row.

Hutchins, E. (1996). Cognition in the wild. Cambridge: MIT Press.

Hutchins, E. (1999). Cognitive artifacts. In MIT encyclopedia of the cognitive sciences. Cambridge, MA: MIT Press. Web: http://cognet.mit.edu/library/MITECS.

Jones, C., Dirckinck-Holmfeld, L., \& Lindstrom, B. (2006). A relational, indirect, meso-level approach to CSCL design in the next decade. International Journal of Computer-Supported Collaborative Learning, $1(1), 35-56$.

Kapur, M., \& Kinzer, C. K. (2009). Productive failure in CSCL groups. International Journal of ComputerSupported Collaborative Learning, 4(1), 21-46.

Latour, B. (1990). Drawing things together. In M. Lynch \& S. Woolgar (Eds.), Representation in scientific practice. Cambridge: MIT Press.

Ligorio, M. B., \& Ritella, G. (2010). The collaborative construction of chronotopes during computersupported collaborative professional tasks. International Journal of Computer-Supported Collaborative Learning, 5(4), 433-452.

Lonchamp, J. (2006). Supporting synchronous collaborative learning: A generic, multi-dimensional model. International Journal of Computer-Supported Collaborative Learning, 1(2), 247-276.

Lonchamp, J. (2009). A three-level analysis of collaborative learning in dual-interaction spaces. International Journal of Computer-Supported Collaborative Learning, 4(3), 289-317.

Lund, A., \& Rasmussen, I. (2008). The right tool for the wrong task? Match and mismatch between first and second stimulus in double stimulation. International Journal of Computer-Supported Collaborative Learning, 3(4), 387-412.

Merleau-Ponty, M. (1945/2002). The phenomenology of perception (C. Smith, Trans. 2 ed.). New York, NY: Routledge.

Norman, D. (1991). Cognitive artifacts. In J. Carroll (Ed.), Designing interaction. Cambridge: Cambridge University Press.

Orlikowski, W. J. (2008). Using technology and constituting structures: A practice lens for studying technology in organizations. In M. S. Ackerman, C. A. Halverson, T. Erickson \& W. A. Kellogg (Eds.), Resources, co-evolution and artifacts. (pp. 255-305): Springer.

Pathak, S. A., Kim, B., Jacobson, M. J., \& Zhang, B. H. (2011). Learning the physics of electricity: A qualitative analysis of collaborative processes involved in productive failure. International Journal of Computer-Supported Collaborative Learning, 6(1), 57-73.

Stahl, G. (2006). Group cognition: Computer support for building collaborative knowledge. Cambridge: MIT Press.

Suthers, D. D. (2006). Technology affordances for intersubjective meaning making: A research agenda for CSCL. International Journal of Computer-Supported Collaborative Learning, 1(3), 315-337.

van der Pol, J., Admiraal, W., \& Simons, P. R. J. (2006). The affordance of anchored discussion for the collaborative processing of academic texts. International Journal of Computer-Supported Collaborative Learning, 1(3), 339-357.

Vygotsky, L. (1930/1978). Mind in society. Cambridge, MA: Harvard University Press. 